\title{
Partial suturectomy for phenotypical craniosynostosis caused by incomplete fusion of cranial sutures: a novel surgical solution
}

\author{
David C. Lobb, MBChB, ${ }^{1}$ Smruti K. Patel, MD, ${ }^{2}$ Brian S. Pan, MD, ${ }^{1}$ and Jesse Skoch, MD² \\ Divisions of ${ }^{1}$ Plastic Surgery and ${ }^{2}$ Pediatric Neurosurgery, Cincinnati Children's Hospital Medical Center, Cincinnati, Ohio
}

\begin{abstract}
OBJECTIVE Patients presenting with head shape changes phenotypical for craniosynostosis may have incomplete fusion of the involved sutures. The surgical literature is lacking in appropriate management strategies for these patients. In this paper, the authors evaluate their experience with a novel treatment strategy: suturectomy of only the fused portion followed by helmeting therapy in patients with skull deformity secondary to incomplete suture synostosis.
\end{abstract}

METHODS Patients with craniosynostosis with incomplete suture fusion requiring operative intervention between 2018 and 2020 were included for evaluation. Patients were selected for partial suturectomy if the patent portion of the suture had a normal appearance. All patients underwent craniectomy of the involved portion of the synostosed suture. Intraoperative ultrasound was used to reassess the degree of fusion at the time of surgery and incision planning. A 2- to 3-cm strip craniectomy was performed under direct visualization through a single minimal access incision. Postoperative helmeting was utilized for all patients. Demographic and perioperative data were collected, including laser scan data in the form of cranial index $(\mathrm{Cl})$ and cranial vault asymmetry (CVA), defined as the difference between two diagonal measurements, from the frontozygomaticus to the opposite eurion.

RESULTS Four males and 1 female with a mean age of 2.8 months (range 1.1-3.9 months) at presentation were included. All patients had incomplete sagittal synostosis (one patient also had an incomplete left lambdoid synostosis and another had an incomplete left coronal synostosis). The mean age at surgery was 3.5 months (range 2.0-4.7 months) without any major complications. All patients were compliant with postoperative helmeting. The average age at the last follow-up was 12.8 months (range 5.3-23.7 months) with a mean follow-up duration of 9.3 months (range 0.5-19.6 months). Final laser scan evaluations were available for 3 patients and showed an improvement of the $\mathrm{Cl}$ from an average of 71.3 (range $70-73$ ) to 84.3 (range 82-86). The CVA improved from an average of $9.67 \mathrm{~mm}$ (range 2-22 $\mathrm{mm}$ ) to $1.67 \mathrm{~mm}$ (range 1-2 mm).

CONCLUSIONS Minimally invasive direct excision of the involved portion of fused cranial sutures followed by helmet therapy for phenotypical craniosynostosis is a safe and effective treatment strategy. This technique is suitable for very young patients and appears to offer similar outcomes to complete suturectomy. Further studies are required to see if this approach reduces the deformity severity for patients requiring vault remodeling later in life.

https://thejns.org/doi/abs/10.3171/2021.1.FOCUS201024

KEYWORDS craniosynostosis; minimally invasive; endoscopic suturectomy; partial fusion; cranial vault; helmeting

$\mathrm{C}$ RANIOSYNOSTOSIS is the premature fusion of the cranial sutures and is reported to occur in about 1 in 2500 births. The sagittal suture is most commonly affected (approximately 40\%), while isolated lambdoid fusions are rare $(<1 \%) .^{1-3}$ Left untreated, an abnormal head shape caused by craniosynostosis may increase intracranial pressure or impair intellectual development and may cause psychosocial anxiety. Interventions are aimed at restoring a normal head shape while allowing for proper growth and development of the brain. Craniosynostosis caused by partial fusion of a cranial suture and its relationship to intracranial pathology is unclear, although we have seen that partial fusions can produce significant cranial deformity. In a recent work by Boyajian et al., ${ }^{4}$ just less than one-third of their patients diagnosed with craniosynostosis had a partial-suture fusion, with the incidence appearing to decrease with age. However, the surgical literature lacks clarity about optimal management strategies for patients

ABBREVIATIONS 3D HCT = 3D head CT; $\mathrm{Cl}=$ cranial index; CVA = cranial vault asymmetry.

SUBMITTED December 1, 2020. ACCEPTED January 5, 2021.

INCLUDE WHEN CITING DOI: 10.3171/2021.1.FOCUS201024. 
TABLE 1. Demographic and operative data with outcomes data to date

\begin{tabular}{|c|c|c|c|c|c|c|c|c|c|c|c|c|}
\hline $\begin{array}{l}\text { Patient } \\
\text { No. }\end{array}$ & Sex & $\begin{array}{l}\text { Age at 1st } \\
\text { Consultation } \\
\text { (days) }\end{array}$ & $\begin{array}{c}\text { 3D HCT } \\
\text { Diagnosis }\end{array}$ & $\begin{array}{l}\text { Age at } \\
\text { Surgery } \\
\text { (days) }\end{array}$ & $\begin{array}{l}\text { Method } \\
\text { of Bone } \\
\text { Removal }\end{array}$ & $\begin{array}{l}\text { Duration } \\
\text { of FU } \\
\text { (days) }\end{array}$ & $\begin{array}{l}\text { Age at } \\
\text { Last FU } \\
\text { (days) }\end{array}$ & $\begin{array}{c}\text { Duration of } \\
\text { Helmeting } \\
\text { (days) }\end{array}$ & $\begin{array}{l}\text { Preop } \\
\mathrm{Cl}\end{array}$ & $\begin{array}{c}\text { Final } \\
\mathrm{Cl}\end{array}$ & $\begin{array}{c}\text { Delta } \\
\mathrm{Cl}\end{array}$ & Comorbidities \\
\hline 1 & Male & 117 & $\begin{array}{l}\text { Partial anterior } \\
\quad \text { sagittal }<50 \%\end{array}$ & 123 & Drilled out & 589 & 712 & 180 & 70 & 82 & 12 & $\begin{array}{l}\text { Premature birth, } \\
\text { ventricular } \\
\text { septal defect, } \\
\text { hemangioma }\end{array}$ \\
\hline 2 & Male & 33 & $\begin{array}{c}\text { Partial anterior } \\
\text { sagittal }>50 \% \text {, } \\
\text { partial It lamb- } \\
\text { doid }<50 \%\end{array}$ & 62 & Drilled out & 440 & 502 & 237 & 71 & 85 & 14 & None \\
\hline 3 & Male & 83 & $\begin{array}{l}\text { Partial anterior } \\
\quad \text { sagittal }<50 \%\end{array}$ & 109 & Drilled out & 240 & 349 & 240 & 73 & 86 & 13 & None \\
\hline 4 & Female & 84 & $\begin{array}{l}\text { Partial anterior } \\
\quad \text { sagittal }<50 \%\end{array}$ & 94 & $\begin{array}{l}\text { Bone scis- } \\
\text { sors }\end{array}$ & 107 & 201 & NA & 74 & NA & NA & None \\
\hline 5 & Male & 109 & $\begin{array}{c}\text { Partial anterior } \\
\text { sagittal }<50 \% \text {, } \\
\text { partial It coro- } \\
\text { nal }<50 \%\end{array}$ & 141 & $\begin{array}{l}\text { Kerrison } \\
\quad \& \text { bone } \\
\text { scissors }\end{array}$ & 16 & 157 & NA & NA & NA & NA & None \\
\hline $\begin{array}{l}\text { Mean } \\
\text { age } \\
\text { (mos) }\end{array}$ & & 2.8 & & 3.5 & & 9.3 & 12.8 & 7.3 & & & & \\
\hline
\end{tabular}

$\mathrm{FU}=$ follow-up; $N A=$ not applicable.

with partial-suture fusion. Our working assumption is that most surgeons treat partial fusions with significant skull shape changes in the same way that they treat complete fusions, given that they can produce similar skull growth restrictions. In this article, we present our experience with a novel treatment strategy: focused and limited suturectomy of only the fused portion of the cranial suture, followed by helmeting, in patients presenting with incomplete suture synostosis and significant skull deformity.

\section{Methods \\ Patient Selection}

All patients presenting to the senior author (J.S.) for initial assessment of an abnormal head shape between June 2018 and August 2020 were considered for inclusion. A diagnosis of craniosynostosis was made using clinical history, examination, and verification by $3 \mathrm{D}$ head $\mathrm{CT}$ (3D HCT). Patients were considered eligible for partial suturectomy if 1) less than $50 \%$ of the suture was fused on 3D HCT; 2) the fused region was relatively contiguous; and 3) the remaining patent suture gap was similar in size to the infant's own nonpathological sutures. Based on institutional experience, we offered minimally invasive suturectomy with postoperative helmeting for patients up to 6 months of age at the time of surgery for sagittal craniosynostosis and up to 4 months for other sutures. We applied these thresholds to patient selection in this cohort while striving to perform these procedures as soon as possible after diagnosis to avoid progression of suture fusion. All procedures were performed within 1 month of the initial consultation (Table 1). Exclusion criteria included suture fusion of more than $50 \%$ (these patients underwent complete strip craniectomy), medical contraindication for early surgery, or if postoperative helmet therapy was not deemed possible for socioeconomic reasons.

\section{Preoperative Workup}

Three-dimensional HCT scans were obtained in all cases for preoperative evaluation of the craniosynostosis type and morphology. It is also our institutional practice to obtain these scans to determine the presence of incidental intracranial pathology which may warrant additional intervention such as shunt placement. ${ }^{5}$ A baseline cranial ultrasound study was obtained preoperatively as a reference for intraoperative ultrasonography. Per our protocol, all patients underwent basic preoperative laboratory workup, including assessment of blood counts, chemistry, and coagulation profiles.

\section{Surgery}

After induction of general anesthesia, patients were placed on a padded cerebellar head holder in a position that optimized access to the fused suture region of interest. Using ultrasound, a neuroradiologist and sonographer localized the precise region of sutural fusion and marked this on the scalp. A small linear incision was planned that would allow access to the fused region and adjacent normal borders on both sides while also allowing conversion to endoscope-assisted full suturectomy if required intraoperatively. The patient was prepped and draped, and the procedure was performed as would be executed for traditional minimally invasive complete suturectomy, except that bone was removed without the use of an endoscope and only at the point of suture fusion. Where necessary, 

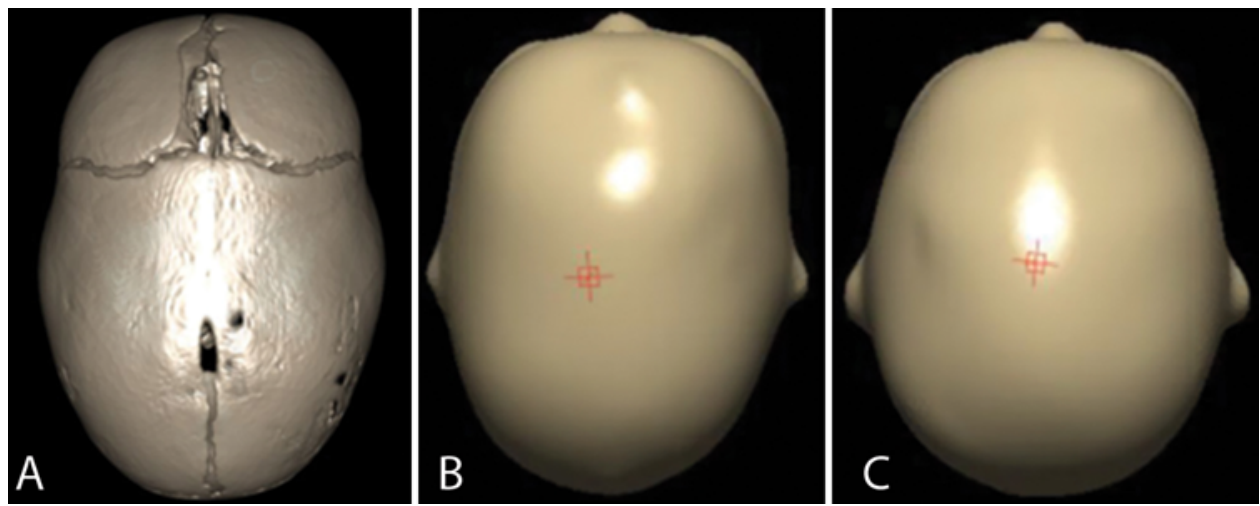

FIG. 1. A: Preoperative CT scan of patient 3 in this series, demonstrating partial sagittal synostosis with phenotypical scaphocephaly. B and C: Pre- (B) and postoperative (C) laser scans of a patient in this series who underwent partial suturectomy for an incompletely fused sagittal synostosis.

for longer fusions, an illuminated angled retractor blade was used and bone was removed by drilling, Kerrison punch rongeurs, or bone scissors. After suturectomy was completed, the surgical field was irrigated with antibiotics, hemostasis was ensured, and the scalp was closed.

\section{Helmet Therapy}

An independent third-party helmet service was used for helmet fitting and management. Helmet specialists were instructed to build helmets to the same specifications that would typically be used for normalizing head shape after routine endoscope-assisted suturectomy cases. Helmets were applied on postoperative day 4 and titrated up over a week to be worn a maximum of 23 hours per day. Patients were evaluated every 3 months, and helmets were discontinued using the same protocol and criteria as standard endoscopic suturectomy patients in our practice. Laser scans were obtained near the time of each 3 -month interval visit.

\section{Data Collection and Analysis}

Demographic and follow-up data were collected (Table 1). Laser scan data from helmet therapy were collected including the cranial index (CI); cranial vault asymmetry (CVA), defined as the difference between two diagonal measurements, from the frontozygomaticus to the opposite eurion; as well as 3D renderings of the head shape from 3 patients who had completed the postoperative helmet protocol. Descriptive analysis was performed on all 3 patients who completed helmeting therapy to highlight changes in the CI and CVA.

\section{Results}

Five patients presenting for surgical correction of partial-suture craniosynostoses were included. Patient demographics include 4 males and 1 female with an average age of 2.8 months (range 1.1-3.9 months) at presentation. All patients were diagnosed with incomplete sagittal synostosis; one patient was also diagnosed with an incomplete left lambdoid synostosis, while another was also diagnosed with an incomplete left coronal synostosis (Table 1). All patients underwent excision of the involved portions at an average age of 3.5 months (range 2.0-4.7 months). The average blood loss was $9.6 \mathrm{ml}$ (range 5-15 ml) compared with $28.6 \mathrm{ml}$ (range 8-70 ml) for the 5 most recent endoscopic strip craniectomies performed by the senior author. There were no intraoperative or early postoperative complications including reoperations, postoperative fluid collections, or wound healing complications. One patient experienced skin irritation during titration of helmet therapy that resolved without intervention. The average age at the last follow-up was 12.8 months (range 5.3-23.7 months) with an average follow-up duration of 9.3 months (range $0.5-19.6$ months).

All patients were compliant with postoperative helmeting throughout the postoperative period. The average length of postoperative helmeting was 7.3 months (range 6.0-8.0 months) for the first 3 patients in the cohort who have completed helmet therapy (the remaining 2 patients have yet to complete therapy). Final laser scan evaluations were available from the first 3 patients in the cohort (including the patient with the lambdoid synostosis) (Fig. 1). Analysis showed an improvement in the CI from an average of 71.3 (range 70-73) to 84.3 (range 82-86). The CVA improved from an average of $9.67 \mathrm{~mm}$ (range 2-22 $\mathrm{mm}$ ) to $1.67 \mathrm{~mm}$ (range 1-2 $\mathrm{mm}$ ). In all cases, intraoperative evaluation of the fused bone segment correlated well with the preincisional ultrasound delineation. The width of all craniectomies was approximately $2 \mathrm{~cm}$.

\section{Discussion}

The etiology of craniosynostosis and the mechanisms by which a cranial suture fuses prematurely remain complex and poorly understood. This variation is reflected in the disparate clinical presentations ranging from mild deformational change with development of late singlesuture synostosis, to complex syndromic presentations with multiple-suture fusions and organic neurological sequelae. Moreover, the incidence, impact, and management of craniosynostosis caused by partial fusion of a suture has not been well described in the literature. To our knowledge, this paper is the first to demonstrate the feasibility of partial-suture resection followed by helmet therapy for treatment of partial-suture synostosis. This novel 


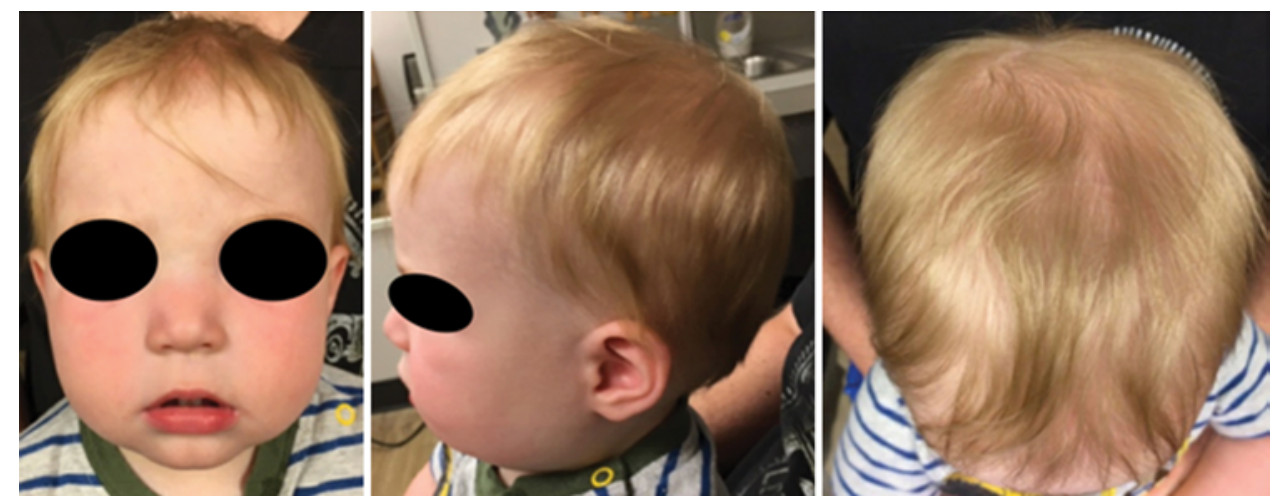

FIG. 2. Postoperative images of patient 3 at 11.6 months after minimally invasive partial suturectomy of his sagittal synostosis, demonstrating excellent correction after completion of helmet therapy.

surgical solution, through a small, single scalp incision, appears to be an effective minimally open approach that is well tolerated in the very young and does not require the use of endoscopic equipment. Additionally, the more limited subgaleal and epidural dissection necessary for an ultrasound-guided focused suturectomy, compared with a complete endoscopic suturectomy, should minimize blood loss, including decreased potential space for postoperative hematoma formation. Indeed, when we compared our intraoperative blood loss for those patients in this series to the 5 most recent endoscopic complete strip craniectomies, we found a reduced average blood loss of $9.6 \mathrm{ml}$ compared with $28.6 \mathrm{ml}$. Furthermore, while a rare occurrence, persistent bony defects occasionally requiring cranioplasty can occur with endoscopic suturectomy. We hypothesize that this limited technique focusing only on the abnormal fusion area could reduce the risk of persistent defects.

As demonstrated by animal models of craniosynostosis, premature fusion may begin at a single site along the suture and then progress outward from that site. ${ }^{6}$ This phenomenon would explain the progression in suture fusion seen with age. ${ }^{4}$ We have shown that early surgical intervention by direct excision of the site of suture fusion followed by helmet therapy is a feasible option to correct the morphological changes seen in children with craniosynostosis. In all cases in which final data could be obtained, the cranial length, originally excessive due to partial sagittal suture fusion, decreased with concomitant widening of the skull. The postoperative skull shape was visibly rounded, with an absence of frontal bossing and occipital protuberance (typical hallmarks of scaphocephaly) (Fig. 2). There was no evidence of relapse or recurrence of suture fusion at the site of surgery or at other sites along the involved suture, suggesting that a nidus for suture fusion may exist, which can be excised early on. This is a finding that may not be appreciated in the setting of multifocal suture pathology.

In each case, the anterior portion of the sagittal suture was involved. It would be interesting to see if this finding is replicated in larger series studies, and, if so, this may prove a focus for further research. Additionally, the relatively high incidence of multiple-suture involvement in this cohort, 2 of 5 patients for an incidence of $40 \%$, was an unexpected finding. In a series of 518 cases of craniosynostosis, Greene et al. ${ }^{7}$ described only 39 patients with nonsyndromic multisuture synostosis for an incidence of $7.5 \%$. In our cohort, in addition to a partially fused sagittal suture, one patient had a partially fused coronal suture while another had a partially fused left lambdoid suture. Of the cases outlined by Greene et al., these specific combinations were reported to have occurred in only 5 patients, 4 with unilateral coronal-sagittal suture fusions and 1 with unilateral lambdoid-sagittal suture fusions.

Limitations of the present work include the low number of patients, largely due to the relative rarity of this presentation, and the incomplete long-term outcomes data for 2 of the 5 patients. In addition, due to our small surgical cohort, the results of this study cannot be applied to a syndromic cohort. Furthermore, the effect of surgical intervention on improvement in neurological function is unclear. Based on the limited literature, this particular relationship has generally proved difficult to ascertain. Further research will also be required to ensure that the absence of relapse remains a constant. These partial fusion cases may also prove interesting in genetics research given that differential gradients of RNA expression may exist that may be amenable to investigation following a partial suturectomy procedure.

\section{Conclusions}

Minimally invasive direct excision of the involved portion of fused cranial sutures followed by helmet therapy for phenotypical craniosynostosis is a safe and effective treatment strategy in the setting of partial-suture fusion. This technique is suitable for very young patients and appears to offer similar outcomes to complete suturectomy. Further studies are required to see if this approach reduces the severity of deformity for patients requiring cranial vault remodeling later in life.

\section{References}

1. Armand T, Schaefer E, Di Rocco F, et al. Genetic bases of craniosynostoses: an update. Neurochirurgie. 2019;65(5):196-201.

2. Wilkie AOM, Byren JC, Hurst JA, et al. Prevalence and complications of single-gene and chromosomal disorders in craniosynostosis. Pediatrics. 2010;126(2):e391-e400. 
3. Selber J, Reid RR, Chike-Obi CJ, et al. The changing epidemiologic spectrum of single-suture synostoses. Plast Reconstr Surg. 2008;122(2):527-533.

4. Boyajian MK, Al-Samkari H, Nguyen DC, et al. Partial suture fusion in nonsyndromic single-suture craniosynostosis. Cleft Palate Craniofac J. 2020;57(4):499-505.

5. Magge KT, Magge SN, Keating RF, et al. Incidental findings on preoperative computed tomography for nonsyndromic single suture craniosynostosis. J Craniofac Surg. 2014;25(4): $1327-1330$

6. Mooney MP, Shand JM, Burrows A, et al. Rescue of premature coronal suture fusion with TGF- $\beta 2$ neutralizing antibody in rabbits with delayed-onset synostosis. Cleft Palate Craniofac J. 2018;55(6):844-855.

7. Greene AK, Mulliken JB, Proctor MR, et al. Phenotypically unusual combined craniosynostoses: presentation and management. Plast Reconstr Surg. 2008;122(3):853-862.

\section{Disclosures}

The authors report no conflict of interest concerning the materials or methods used in this study or the findings specified in this paper.

\section{Author Contributions}

Conception and design: Skoch. Acquisition of data: Skoch, Lobb, Pan. Analysis and interpretation of data: all authors. Drafting the article: Lobb, Patel. Critically revising the article: all authors. Reviewed submitted version of manuscript: all authors. Approved the final version of the manuscript on behalf of all authors:

Skoch. Statistical analysis: Lobb. Administrative/technical/material support: Patel. Study supervision: Skoch.

\section{Supplemental Information}

\section{Abstract Presentations}

An abstract detailing the outcomes from the first four patients in this series has been accepted for oral presentation at the American Cleft Palate-Craniofacial Association's 78th Annual Meeting, April 29-May 1, 2021.

\section{Correspondence}

Jesse Skoch: Cincinnati Children's Hospital Medical Center, Cincinnati, OH. jesse.skoch@cchmc.org. 